\title{
Endogenous Distortions in Product and Labor Markets
}

Martin Rama

Guido Tabellini
The World Bank

Policy Research Department

Poverty and Human Resources Division January 1995
Product and labor market distortions move in the same direction in response to economic and social changes. Conditionality by foreign agencies should target product market distortions. Once they are removed or diminished; labor market distortions will adjust in the desired direction. 


\section{Summary findings}

Rama and Tabellini use the common agency approach to analyze the joint determination of product and labor market distortions in a small (developing) open economy.

Capital owners and union members lobby the government on tariffs and minimum wages, while factors of production in agriculture (the informal sector) are not orgenized. The government cares about social welfare, but also values the contributions (monetary or else) made by organized groups.

Rama and Tabellini show that product and labor market distortions move in the same direction in response to changes in the relevant econor ic and political parameters, and that the level of those distortions is not modified by social pacts between capital and labor.

They also show that conditionality by foreign agencies should target product market distortions, not labor market distortions. Labor market distortions ought not to be targeted because they are second best: they are the optimal response to the product market distortions. Labor market distortions are likely to adjust in the desired direction once product market distortions are removed or diminished.

This paper - a product of the Poverty and Human Resources Division, Policy Research Department - is part of a larger effort in the department to analyze the implications of labor market distortions. The study was funded by the Bank's Research Support Budget under the research project "The Impact of Labor Market Policies and Institutions on Economic Performance" (RPO 67846). Copies of this paper are available free from the World Bank, $1818 \mathrm{H}$ Street NW, Washington, DC 20433. Please contact Sheila Fallon, room N5-033, extension 38009 (36 pages). January 1995. 


\title{
Endogenous Distortions in Product and Labor Markets *
}

\author{
Martin Rama (The World Bank)
}

Guido Tabellini (Bocconi University and IGIER)

* This paper is part of the research project on "The Impact of Labor Market Policies and Institutions on Economic Performance", supported by the World Bank Research Committee through grant RPO 678-46. We are grateful to Ishac Diwan and Yoram Weiss for helpful comments. 


\section{Introduction}

This paper has two goals. On the positive side, to explain observed trade and labor market policies in developing countries. On the normative side, to address an institution design question; namely, how to structure coidditionality clauses relating to these policies in aid or loan programs from multi-lateral organizations like the World Bank. To achieve these goals. the paper sudies the joint determination of product and labor market distortions. Labor market policies are indeed natural substitutes or complements (depending on the instruments) of product market policies. Moreover, both policies often have the sane political determinants.

The joint analysis of endogenous product and labor market distortions is particularly relevant for developing countries. Nowhere is the link between these distortions more obvious than in the resistance of labor unions to trade liberalization. Attempts to reduce or eliminate trade barriers in developing countries have often led to strikes, demonstrations and even riots by organized labor. The downward rigidity of wages in formerly protected sectors, in turn, has been pointed out as a major source of recidivism. More generally, a large number of researchers and practitioners believe that not tackling product and labor market distortions simultaneously is a recipe for reform failure.

Concerns about competitiveness in industrial countries have also resulted in a link between trade and labor market policies, although with an unexpected twist. In the aftermath of GATT's Uruguay round, which should lead to a significant liberalization of world trade, the enforcement of labor standards in developing countries is seen by many as a safeguard against unfair competition. In this spirit, the U.S. recently approved legislation requiring its Executive Directors in multi-lateral orginnizations like the World Bank to make the observance of workers' rights, including the right to form labor unions, a condition of lending.

In between those who would like to push developing countries to deregulate their labor markets and those who would rather encourage them to guarantee workers rights, some others see a positive role 
for "social pacts" between capital and labor. They usually point to the Pacto Solidaridad as one of the key ingredients in the success of Mexico's structural reform and trade liberalization. However, the merits and demerits of these pacts are controversial too. Although social welfare would be higher if capital and labor cooperated to reduce social tensions, this cooperation could actually be a form of collusion at the expense of those sectors or groups not represented in the social pact.

Our method of analysis relies on the common agency model pioneered by Bernheim and Whinston (1986), and applied to trade policy by Grossman and Helpman (1994). In this model, the government is the agent who sets economic policy. Various interest groups act as principals and confront the government with contribution schedules, namely with functions mapping the economic policy into actions valued by the government. These actions admit several alternative interpretations: they can be bribes, campaign contributions, or even support demonstrations. Two things are essential. First, that the government values the actions more than what they cost to the lobbies. Second, the timing: first the lobbies simultaneously commit to contribution schedules; next, the government, having observed these schedules, sets economic policy. The interest groups thus play Nash against each other, but take into account the influence of their choices on the government.

Grossman and Helpman (1994) apply this approach to a small open economy with many sectors. They only study trade policy. The principals are the owners of fixed factors in each sector, while consumers are not organized in lobbies. By contrast, our paper studies a small (developing) open economy with only two sectors: manufacturing and agriculture, or better, a formal and organized sector, and an informal sector. The government controls two policy instnuments: a tariff and a minimum wage. Both policies only affect the manufacturing sector. There are two organized interest groups: capital owners, and union members. They too are only present in the manufacturing sector. Factors of production in agriculture (the informal sector) are not organized in a political lobby. Thus, unlike Grossman and Helpman (1994) our paper focuses on how different factors in the same sector lobby the 
government for distortionary policies that, on the one hand create rents (the tariff), and on the other hand determine the distribution of these rents (the minimum wage.)

We obtain several results. First, a set of positive results, concerning the economic and political determinants of trade and labor market policies. Despite the conflict of interest on labor market policies, there is complementarity between the two policy instruments: in equilibrium, labor and product market distortions always move in the same direction in response to exogenous changes in any of the relevant economic and political parameters. The economic parameters are those determining the extent of the deadweight losses resulting from distortions. The political parameters are related to the size of the interest groups and to the value the government attaches to their contributions. In the general case, the equilibrium level of distortions is not modified if capital owners and unionized workers decide to cooperate. However, social pacts may reduce the amount of resources wasted in lobbying. This is because by playing Nash, interest groups are to some extent lobbying against each other (particularly, regarding the minimum wage), an inefficiency that can be avoided through cooperation.

Second, we obtain a set of normative results, concerning the optimal design of conditionality clauses by a multi-lateral agency. Under plausible assumptions, the multi-lateral agency should target product market distortions, but not labor market distortions. That is, labor market distortions are second best: they are the optimal response to the product market distortions. Thus, if a conditionality clause succeeds in removing or reducing a tariff, the labor market policy will endogenously adjust and also move in the right direction. This result follows from a set of assumptions implying that the economic agents not organized in a political lobby (usually workers in the informal sector) are harmed by trade policy but not by the labor market policy. If this feature of the model is removed, then the optimal conditionality clause should target both product and labor market distortions, but the optimal targeting of labor markets is generally ambiguous and depends on features of the economy that might be hard to assess. The optimal targeting of commercial policy, on the other hand, should always be in favor of free trade. This 
result thus provides support for the existing practice of the World Bank, which is characterized by a strong focus on trade liberalization, but little emphasis on labor market reforms. When economic policies depend on which party is in office, conditionality may also affect product and labor market distortions through election outcomes. Because transfers from abroad are higher the lower are trade barriers, conditionality biases the choice of rational voters in favor of the more free trade party.

The paper is organized as follows. Section 2 lays out the model summarized above. The welfare effects of economic policies are described in section 3. The equilibrium is characterized in section 4, while section 5 discusses its comparative statics properties in response to changes in observable features of the economy. Section 6 evaluates the economic and political consequences of a social pact between capital owners and union members. The optimal design of conditionality clauses is discussed in section 7. Section 8 extends the model to an electoral competition between left-wing and right-wing politicians, and sector 9 contains some concluding remarks.

\section{The Model}

Consider an economy with two sectors, which will be identified as agriculture and manufacturing for simplicity. The nature of the goods produced by these two sectors has in fact little importance. Their relevant feature is whether individuals in these sectors are organized in interest groups or not. It is assumed that workers in agriculture undertake no collective action, while both workers and capital owners in manufacturing do. Therefore, the sectoral distinction accounts here for institutional heterogeneity. The hypothesis that different sectors have different institutions is pervasive in development economics. Depending on the authors, the sectors are labelled as "modern" and "traditional", "urban" and "rural", or "formal" and "informal". Whatever the chosen classification, it is relatively easy to pinpoint features of the production process (such as spatial agglomeration, or the number of individuals in -Ived) which make it easier to overcome the obstacles to collective action in one of the sectors than in the other. 
Total population is normalized to one. A fraction $\alpha^{K}$ of the individuals own the capital used in * manufacturing and do not need to work: as wage earners to make a living. These individuals are organized in a producers' association. A fraction $\alpha^{U}$ of the individuals are manufacturing workers, organized in a trade union. Finally, the remaining $1-\alpha^{\mathrm{K}}-\alpha^{\mathrm{U}}$ individuals work in agriculture and have no organization to represent them.

All individuals have the same preferences over consumption goods, represented by the following objective function:

$$
\mathbf{u}^{1}=\mathbf{a}^{i}+\mathbf{U}\left(c^{i}\right)
$$

where $u^{i}$ is the utility level of individual $i, a^{i}$ is his or her consumption of the agricultural good, and $c^{i}$ is his or her consumption of the manufactured good. The function $U($.$) is increasing and concave$ Utility is maximized subject to the budget constraint:

$$
I^{\prime} \geq a^{l}+p c^{1}
$$

where $\mathrm{I}^{\mathrm{i}}$ is the net income of individual $\mathrm{i}$, to be defined below, and $\mathrm{p}$ is the domestic relative price of the manufactured good. The price of the agricultural good is normalized to unity. Given the specification chosen for the utility function $u^{i}$, it follows that consumption of the manufactured zood does not depend on income:

$$
c^{i}=C(p) \text { for all } i, c_{p}<0
$$

where a subscript denotes a derivative. 
Agricultural goods are produced with labor only. Wages in agriculture are normalized to unity. Manufactured goods are produced with capital $K$ and labor $L$, according to a concave function $F(K, L)$. Profit maximization by firms implies that for a given capital stock, employment in manufacturing depends on the domestic price $p$ of the manufactured good and on the wage $w$ paid to the workers in this sector:

$$
P_{L}(K, L)=w / p
$$

Since total population was normalized to one, $\mathrm{L}\left(s \alpha^{\mathrm{U}}\right)$ represents the fraction of total population actually employed in manufacturing.

The government has two policy instruments: import tariffs, $\mathrm{p}-\mathrm{p}^{*}$, where $\mathrm{p}^{*}$ is the international price of manufacturing goods; and minimum wages in the manufacturing sector, w. Since wages in agriculture are unity, the wage differential $w-1$ measures the government intervention in the labor market. For simplicity, we assume that the only government revenues are the proceeds $T$ of import tariffs on manufactured goods: 1

$$
T \equiv(p-p)[C(p)-F(K, L)]
$$

Tariff revenue is distributed to individuals belonging to different groups according to exogenous weights. Specifically, the government transfer to an individual who belongs to group jis $\phi^{j} T$, with $\phi^{j} \geq 0$ and such that:

$$
\alpha^{\mathrm{K}} \phi^{\mathrm{K}}+\alpha^{\mathrm{U}} \phi^{\mathrm{U}}+\left(1-\alpha^{\mathrm{X}}-\alpha^{\mathrm{U}}\right) \phi^{\wedge}=1
$$

1 The results would be unchanged if there was an export subsidy, rather than an import tariff, on manufactured goods. In this case, $\mathrm{T}$ would be negative. 
Two particular cases will be highlighted in what follows. The case where $\phi^{j}=1$ for all $j$ corresponds to the standard international trade model, where tariff revenues are assumed to be distributed evenly across the population. The case where $\phi^{A}=0$ and $\phi^{K}=\phi^{U}=1 /\left(\alpha^{K}+\alpha U\right)$ may fit better a set up in which only the individuals who are organized in interest groups benefit from redistribution.

Individuals belonging to different groups differ in their net income, which includes their primary factor earnings, plus the government transfer, if any, and (possibly) minus a voluntary contribution to the government to influence its economic policies.

Since wages in agriculture are normalized to one, the income of an individual working in this sector is:

$$
I^{\wedge} \pm 1+\phi^{\wedge} T(p, L)
$$

By assumption, agricultural workers do not make any contributions to influence economic policy outcomes.

Capital owners in the manufacturing sector earn profits in addition to the transfer $\phi^{\mathrm{K}} \mathrm{T}$. They pay contributions $\lambda^{K}$ to the government, contingent on the chosen economic policies: $\lambda^{K}$ is a schedule mapping every pair $(p, w)$ into a contribution level. Under these assumptions, the net individual income of a capital owner is:

$$
I^{K} \equiv \frac{p P(K, L)-w L}{\alpha^{K}}+\phi^{K} T(p, L)-\frac{\lambda^{K}(p, w)}{\alpha^{K}}
$$

Finally, the expected income of workers who are organized in unions depends on how the minimum wage $w$ affects employment $L$ in manufacturing. The higher is $w$, the lower is employment in manufacturing and, consequently, the higher is the probability for a union member to end up working 
in agriculture. ${ }^{2}$ The expected wage of a union member is a weighted average of the wages in the two sectors, $w$ and 1 , with weights $L / \alpha U$ and $\left(\alpha^{U}-L\right) / \alpha^{U}$ respectively. Therefore, his or her expected income is:

$$
I^{U}=1+\frac{(w-1) L}{\alpha^{U}}+\phi^{U} T(p, L)-\frac{\lambda^{U}(p, w)}{\alpha^{U}}
$$

where $\lambda^{U}$ are contributions paid by trade unions to the government. These contributions are treated in the same way as those by capital owners. Because of risk neutrality, unionized workers are only concerned about their expected net income (see Oswald, 1985), plus naturally the consumption distortions resulting from government policies.

The government cares about aggregate well-being, but also about the support it gets from interest groups. Its objective function $V^{G}$ can thus be written as:

$$
V^{\mathcal{O}}(p, w)=\beta\left[\lambda^{K}(p, w)+\lambda^{\mathrm{V}}(p, w)\right]+\left[Q(p, w)-\lambda^{K}(p, w)-\lambda^{U}(p, w)\right]
$$

where $B>1$ is the weight the government attaches to the support it gets from organized groups, and $\Omega(p, w)$ is the aggregate welfare level that could be attained in the absence of any political contributions:

$$
\Omega(p, w)=\alpha^{K} V^{K}(p, w)+\alpha^{U} V^{U}(p, w)+\left(1-\alpha^{K}-\alpha^{U}\right) V^{\wedge}(p, w)
$$

2 Throughout the paper we assume that in equilibrium $\mathrm{L}<\alpha \mathrm{U}$. 
In equation (9), $v^{j}$ represents the gross indirect utility of an individual belonging to group $J$, i.e. the utility level that would be attained, given the government policies, if he or she did not make any political contribution to the government. Note that $\Omega$ would be the objective function of the social planner in the Pigouvian approach to economic policy. The second term in brackets in (8) is the net aggregate welfare level, obtained by subtracting political contributions from the gross welfare level $8 .{ }^{3}$

Since $B>1$, the government values the contributions more that what they cost the lobbies. By assumption, the government values all contributions the same, no matter whether they come from capital owners or from unionized workers (i.e. there is no class bias). The case of ideological governments is discussed in section 8 below.

Individuals maximize their utility for a given contribution and a given policy, while contributions are decided by the corresponding interest group. The interaction between the interest groups and the government has the structure of a menu auction problem, like the one analyzed by Bernheim and Whinston (1986) or, in a context more similar to ours, by Grossman and Helpman (1994). These authors show that the equilibrium of the endogenous policy game is the policy $(p, w)$ which maximizes both the objective function of the government and those of each lobby.

\section{The Welfare Effects of the Policies}

To understand the properties of the model, we first discuss the welfare effects of product and labor market distortions on individuals belonging to each group. There are direct welfare effects, to the extent that changes in $p$ and $w$ modify the net income of these individuals, as well as the consumption distortions they face. But there are indirect effects too, because employment $L$ in manufacturing depends on the real wage w/p. The labor demand curve represented by (4) implies that $L$ can be written as

3 This simple interpretation of equations (8) and (9) is made possible by the linearity of preferences in the agricultural good. 
$L(p, w)$, with $L_{p}>0$ and $L_{w}<0$, while physical output $F(K, L)$ is a function $Y(p, w)$, with $Y_{p}>0$ and $Y_{w}<0$. Similarly, the definition of tariff revenue in (5) allows writing $T$ as a function $T(p, w)$, with $\mathrm{T}_{\mathrm{p}} \geq 0$ and $\mathrm{T}_{\mathrm{w}} \geq 0.4$

Taking these indirect effects into account, the envelope theorem implies, in the case of agricultural workers:

$$
\begin{gathered}
V_{p}^{\wedge} \equiv \phi^{\wedge} T_{p}-C \geqslant 0 \\
V_{w}^{\wedge} \equiv \phi^{\wedge} T_{w} \geq 0
\end{gathered}
$$

At free trade $\left(p=p^{*}\right), T_{p}=T_{w}=0$, so that $V_{p} A<0$ and $V_{w}^{A}=0$. If agricultural workers receive no transfers from the government $\left(\phi^{A}=0\right)$, their indirect utility always decreases with protection $\left(V_{p} A\right.$ $<0$ ) but is not affected by wage differentials $\left(V_{w}{ }^{A}=0\right)$. If, on the contrary, tariff revenues are distributed evenly to the population $\left(\phi^{\mathrm{A}}=1\right)$, then agricultural workers are still harmed by protection, but they benefit from higher wages in manufacturing. The beneficial effect of higher wages comes form the resulting drop in the domestic supply of manufactured goods, which expands imports and, consequently, tariff revenues. In a more general model, with decreasing marginal productivity of labor in agriculture, this beneficial effect should be weighted against the reduction in agricultural wages that would result from a diminished labor demand in manufacturing. $Y_{p}=-(w / p)^{2} L_{w}$. We implicitly assume that protection is not so high to be on the "wrong" side of the Laffer curve. 
In the case of capital owners, the envelope theorem implies:

$$
\begin{aligned}
& V_{p}^{K}=\frac{Y}{\alpha^{K}}+\phi^{K} T_{p}-C \gtrless 0 \\
& V_{w}^{K}=-\frac{L}{\alpha^{K}}+\phi^{K} T_{w} \gtrless 0
\end{aligned}
$$

Since $Y / \alpha^{K}>0$, when tariff revenues are distributed evenly to the population $\left(\phi^{K}=\phi^{A}=1\right.$ ), capital owners suffer less from increased protection than agricultural workers. The gap in welfare effects between both groups is even larger if agricultural workers do not receive any transfer $\left(\phi^{\mathbf{K}}>{ }_{\phi^{\mathbf{A}}}^{\mathbf{A}}=\mathbf{0}\right)$. At free trade $\left(p=p^{*}\right), T_{p}=T_{w}=0$, and capitalists benefit from protection and are harmed by higher minimum wages, as expected. These results hold when tariffs are positive, provided that capital owners represent a narrow group ( $\alpha^{K}$ small), or that $p$ is sufficiently close to $p^{*}$.

With regard to unionized workers, their indirect utility function is such that:

$$
\begin{aligned}
& V_{p}^{U}=\frac{(w-1) L_{p}}{\alpha^{U}}+\phi^{U} T_{p}-C \gtrless 0 \\
& V_{w}^{U} \equiv \frac{L+(w-1) L_{w}}{\alpha^{U}}+\phi^{U} T_{w} \gtrless 0
\end{aligned}
$$

At free trade $\left(p=p^{*}\right), T_{p}=T_{w}=0$. So, union members can either benefit or suffer from protection depending on whether the induced increase in employment exceeds or falls short of the consumption distortion. The benefits from protection are greater the higher is the minimum wage. In any event, when manufacturing wages are above their agricultural counterparts, unionized workers suffer less from increased protection than agricultural workers, and they can benefit from protection when the wage gap 
$w-1$ is large and union membership $\alpha^{\mathrm{U}}$ is small. Moreover, starting at free trade $\left(p=p^{*}\right)$, union members benefit from wage increases up to the point where the elasticity of labor demand in manufacturing, $\eta_{w}=-L_{w} w / L$, is smaller than unity. The gap between $V_{w} U$ and $V_{w}{ }^{A}$ is amplified if agricultural workers do not receive any transfer from the government $\left(\phi^{\mathrm{U}}>\phi^{\mathrm{A}}=0\right)$. The same happens to the gap between $V_{p} U$ and $V_{p} A$.

Thus, as expected, starting from a policy of free trade and no minimum wage, agriculture is harmed by protection, and capitalists in manufacturing are the primary beneficiaries of protection, even though workers can benefit too if minimum wages are high. Moreover, union members benefit from higher minimum wages in manufacturing while capitalists are harmed by them. Adding revenue distribution changes these simple and intuitive results somewhat. Since union members and capital owners are the groups that actively lobby, it is important to stress that their economic interests are opposite with regard to the minimum wage policy, while they tend to be similar with regard to protection. This plausible feature of the model is reflected in the properties of the equilibrium described in the remainder of the paper.

\section{Characterizing the Equilibrium}

In this section we characterize the equilibrium policies and the equilibrium contributions. First of all, equilibrium policies must be optimal for the government and for the interest groups, given the equilibrium contributions (see Bernheim and Whinston, 1986, and Grossman and Helpman, 1994). Thus, in equilibrium, interest groups make contributions up to the point where the gain from the resulting change in economic policies is exactly offset by the marginal cost of the contributions. 5

5 We only consider differentiable contribution schedules. This point is further discussed below. 


$$
\alpha^{x} V_{p}^{x}=\lambda_{p}^{x}, \alpha^{x} V_{w}^{x}=\lambda_{w}^{x}, x=K, U
$$

On the other hand, the first-order conditions of the government's optimization problem imply:

$$
\begin{aligned}
& v_{p}^{G}=(\beta-1)\left(\lambda_{p}^{K}+\lambda_{p}^{U}\right)+Q_{p}=0 \\
& v_{w}^{G} \equiv(\beta-1)\left(\lambda_{w}^{K}+\lambda_{w}^{U}\right)+Q_{w}=0
\end{aligned}
$$

Combining (11) and (12), and recalling the definition of the social welfare function $\Omega$ in (9), the solution to the government's optimization problem can be re-written as:

$$
\begin{aligned}
& v_{p}^{0}=\beta \alpha^{\mathrm{X}} v_{p}^{\mathrm{K}}+\beta \alpha^{\mathrm{U}} \mathrm{v}_{\mathrm{p}}^{\mathrm{U}}+\left(1-\alpha^{\mathrm{K}}-\alpha^{\mathrm{U}}\right) \mathrm{v}_{\mathrm{p}}^{\mathrm{A}}=0 \\
& V_{w}^{0}=\beta \alpha^{K} V_{w}^{K}+\beta \alpha^{U} V_{w}^{U}+\left(1-\alpha^{K}-\alpha^{U}\right) V_{w}^{\Lambda}=0
\end{aligned}
$$

Therefore, by valuing the contributions of interest groups, the government implicitly maximizes a social welfare function in which different individuals have different weights depending on whether they belong to one of these groups. The more the government values the contributions (i.e. the higher is the parameter B), the greater is the share of interest group members in this social welfare function. A similar result is obtained in Grossman and Helpman (1994) in the context of pure trade policy, and it extends naturally to factor market distortions.

We now discuss the nature and direction of the policy distortions induced by the lobbying activities. The issue is not obvious, because of second-best arguments. With two endogenous distorting policies, it is not clear that welfare improvements would be obtained by moving one instrument in the direction of less intervention, given that the other policy distortion remains intact. In fact, this second- 
best argument is shown to be particularly relevant for the labor market distortion. To see this, rewrite equation (13) as:

$$
\begin{aligned}
& Q_{p}=\frac{\beta-1}{\beta} V_{p}^{\wedge} \\
& D_{w}=\frac{\beta-1}{\beta} V_{v}^{\wedge}
\end{aligned}
$$

Since $\Omega(p, w)$ is the (utilitarian) social welfare function, equation (13') identifies the direction of the equilibrium distortions. Quite intuitively, the distortion is proportional to the welfare effect of the policy on the unrepresented group, the agricultural sector. The cunstant of proportionality depends on how much the government values the contributions by the active lobbies. Combining (10A), (10K) and (10U) with (13), it is possible to show that in equilibrium $v_{p} A<0$. Hence, $\Omega_{p}$ is negative too, which means that the equilibrium tariff is too high from the social welfare viewpoint, given the equilibrium wage level.

Concerning $\mathbf{\Omega}_{w}$, it is necessary to consider whether agricultural workers receive a transfer from the government or not. If they do not $\left(\phi^{A}=0\right)$, then $v_{w}{ }^{A}=0$ (see $(10 A)$ ), which implies $\Omega_{w}=0$. The wage gap $w-1$ therefore represents the second-best labor market distortion, given that tariffs are positive. This efficiency of the labor market distortion results from the fact that the wage level in manufacturing affects only the individuals who are represented by interest groups and, hence, can do something about it. This is not so anymore if tariff revenues are distributed to all the population, because then the welfare of agricultural workers depends on manufacturing wages. Specifically, if $\phi_{A}>0$, then $v_{w} A>0$, thus implying $\Omega_{w}>0$. In this case, although the labor market is distorted, wages in 
manufacturing are still too low. Given the equilibrium tariff, more, and not less, government intervention would be desirable in labor markets. 6

Next, we characterize the equilibrium contributions. Following Grossman and Helpman (1994), we only consider truthful contribution schedules. Only these contributions support "coalition proof" Nash equilibria, and vice-versa all such equilibria are reflected by truthful contributions (see Bernheim and Whinston, 1986). ${ }^{7}$ A truthful contribution schedule has the form:

$$
\lambda^{x}\left(p, w ; z^{x}\right)=\operatorname{Max}\left[0, \alpha^{x} V^{x}(p, w)-z^{x}\right], x=K, U
$$

where $\mathrm{z}^{\mathrm{X}}$ is a scaler. Thus, a truthful contribution pays the government the true welfare effect of the policy, in excess of a reservation value $z^{x}$. By equation (14), not only a truthful contribution function is differentiable (except possibly at 0 ), but its shape is entirely determined by the lobby indirect utility function $\alpha^{x} V^{x i}(p, w)$.

To complete the characterization of the equilibrium, it remains to determine the equilibrium reservation utilities, $z^{x}, x=K, U$. These are pinned down by the requirement that, given the equilibrium contribution of the other group, each lobby is paying the lowest possible contribution (i.e., is setting the largest $\mathrm{z}^{\mathrm{X}}$ ) to induce the government to pursue the equilibrium policy characterized above. For this to be the case, given the equilibrium contribution functions $\lambda^{x}\left(p, w ; z^{x}\right), x=K, U$, the government imust be indifferent between implementing the equilibrium policy and receiving the equilibrium contribution from both lobbies on the one hand, or taking a positive contribution from only

6 In a more general model, in which agricultural wages would be negatively affected by high wages in manufacturing, the sectoral wage differential would tend to be too high. The sign of $\mathbf{\Omega}_{\mathbf{w}}$ would therefore depend on whether the positive effect that higher manufacturing wages have on tariff revenue dominates the negative effect they have on agricultural wages.

7 A "coalition proof" Nash equilibrium is stable to non-binding communication among the players. 
one of the two lobbies, and implementing the policy optimal for that lobby on the other hand. Specifically, let:

$$
\left(p^{x}, w^{x}\right)=\operatorname{Argmax}\left[O(p, w)+(\beta-1) \alpha^{x} V^{x}(p, w)\right], x=K, U
$$

be the policy which is jointly optimal for the government and lobby $x$. With truthful contributions, this is the optimal policy for the government, if it were to take contributions only from lobby $x$. Furthermore, let $\left(p^{0}, w^{0}\right)$ be the equilibrium policy characterized by (13). That is:

$$
\left(p^{0}, w^{0}\right)=\operatorname{Argmax}\left\{Q(p, w)+(\beta-1)\left[\alpha^{x} v^{x}(p, w)+\alpha^{v} v^{v}(p, w)\right]\right\}
$$

Then, the indifference condition stated above can be written as:

$$
\begin{aligned}
& Q\left(p^{0}, w^{0}\right)+(\beta-1)\left[\lambda^{x}\left(p^{0}, w^{0} ; z^{x}\right)+\lambda^{U}\left(p^{0}, w^{0} ; z^{U}\right)\right] \\
& =Q\left(p^{x}, w^{x}\right)+(\beta-1) \lambda^{x}\left(p^{x}, w^{x} ; z^{x}\right), \quad x=K, U
\end{aligned}
$$

The left-hand side of (17) denotes the equilibrium government payoffs; the right-hand side denotes the government payoffs when only one interest group provides contributions.

Inserting the expression for truthful contributions, (14), in (17), and simplifying yields the equilibrium reservation utilities for both lobbies:

$$
\begin{gathered}
(\beta-1) z^{x}=Q\left(p^{0}, w^{0}\right)+(\beta-1)\left[\alpha^{X} V^{X}\left(p^{0}, w^{0}\right)+\alpha^{U} V^{U}\left(p^{0}, w^{0}\right)\right] \\
-Q\left(p^{y}, w^{y}\right)-(\beta-1) \alpha^{y} V^{y}\left(p^{y}, w^{y}\right), x=K, U, x+y
\end{gathered}
$$


The first two terms on the right-hand side of (18) are a measure of the maximum gross welfare (i.e. disregarding the contributions) attainable by the government and the two active lobbies. The last two terms measure the maximum gross welfare attainable by the smaller coalition consisting of the government plus only one lobby. Thus, the equilibrium reservation utilities equal the welfare difference between the coalition inclusive of all the lobbies, and the smaller coalition with only one lobby.

The reservation utility $\mathrm{z}^{\mathrm{x}}$ measures the "rent" that lobby $\mathrm{x}$ can extract from the agency relation with the government. The larger is $\mathrm{z}^{\mathrm{x}}$, the larger is the benefit resulting from the policy distortion that is appropriated by the lobby rather than by the government. The foregoing discussion illustrates that the size of this rent for lobby $x$ depends on how well the government can do with the other lobby alone. Thus, the "economic power" of a lobby is not absolute, but it is relative to that of its competitors. These results are further discussed in section 6 below as well as in Grossman and Helpman (1994). Finally, comparing equations (15) and (16), we see that (18) implies $z^{X}>0, x=K, U$ : in equilibrium both lobbies capture some rents from the agency relation.

Repeating the analysis for $\lambda^{x}$, rather than $z^{x}$, it is also possible to show that $\lambda^{x}\left(p^{0}, w^{0} ; z^{x}\right)>$ $0, x=K, U$, i.e. contributions by both lobbies are strictly positive. To see this, subtract $(\beta-1) \alpha^{x} V^{x}\left(p^{0}, w^{0}\right)$ from both sides of equation (18), which becomes:

$$
\begin{gathered}
(\beta-1)\left[\alpha^{x} V^{x}\left(p^{0}, w^{0}\right)-z^{x}\right]=Q\left(p^{y}, w^{y}\right)+(\beta-1) \alpha^{y} V^{y}\left(p^{y}, w^{y}\right) \\
-Q\left(p^{0}, w^{0}\right)-(\beta-1) \alpha^{y} V^{y}\left(p^{0}, w^{0}\right), x=K, U, x \neq y
\end{gathered}
$$

Equation (15) implies that the right-hand side of (18') is strictly positive. Therefore, in equilibrium, both interest groups actively lobby the government to influence economic policies. 


\section{Comparative Statics}

The model presented in the previous sections can be used to determine the equilibrium level of trade barriers and sectoral wage differentials, as well as to analyze the relationship between these distortions and the value of key parameters of the economy. Equilibrium product and labor market distortions are the values of $\left(p-p^{*}\right) / p$ and $(w-1) / w$ which simultaneously solve the first-order conditions of all the involved economic and political agents. We assume that the solution to this problem is feasible in the sense that contributions by each organized group are not greater than the aggregate income available to the group's members.

By replacing the $V_{x}^{j}$ by their analytical expressions, given by (10A), (10K) and (10U), and by taking (6) into account, the first-order conditions of the government's optimization problem become:

$$
\begin{gathered}
\beta\left[Y+(w-1) L_{p}\right]+\left(\beta-\Delta \phi^{\wedge}\right) T_{p}-(\beta-\Delta) C=0 \\
\beta(w-1) L_{w}+\left(\beta-\Delta \phi^{\wedge}\right) T_{w}=0
\end{gathered}
$$

where:

$$
0<\Delta=(\beta-1)\left(1-\alpha^{\mathrm{X}}-\alpha^{\mathrm{U}}\right)<\beta
$$

and $L_{p}, T_{p}, L_{w}$ and $T_{w}$ are functions of $p$ and $w$ (see footnote 4). After some algebra, this system of equations can be re-written as follows:

$$
\begin{gathered}
\frac{p^{0}-p^{*}}{p^{0}}=\frac{\Delta}{\beta-\Delta \phi^{\wedge}} \cdot \frac{1}{\epsilon_{p}} \cdot\left[\phi^{\wedge} \frac{Y}{C}+\left(1-\phi^{\wedge}\right)\right] \\
\frac{w^{0}-1}{w^{0}}=\frac{\beta-\Delta \phi^{\wedge}}{\beta} \cdot \frac{p^{0}-p^{*}}{p^{0}}
\end{gathered}
$$


where the superscript "0" reminds that this is the equilibrium, and where $\epsilon_{p}=-C_{p} p / C>0$ is the price elasticity of domestic demand for manufactured goods. Note that the second equation in (20) establishes a relation of complementarity between the distortions in product and labor markets. Note also that there would be no distortions at all if $\beta=1$, i.e. if the government did not value contributions by interest groups.

More generally, the comparative statics properties of the model can be analyzed by solving system (20) on the distortions $\left(p^{0}-p^{*}\right) / p^{0}$ and $\left(w^{0}-1\right) / w^{0}$. The partial derivatives of these distortions with respect to the parameters in the model are summarized in Table 1 for the case where tariff revenues are distributed evenly to all the population $\left(\phi^{A}=1\right)$. Results in parenthesis correspond to the case where only the individuals who are organized in interest groups receive transfers from the government. The sign of the partial derivatives in the table is always the same for both distortions, which highlights once more their complementarity.

Product and labor market distortions are higher:

- The smaller is the price-elasticity $\epsilon_{\mathrm{p}}$ of domestic demand for the good produced by the manufacturing sector. A high price elasticity makes it indeed more costly for the government to introduce policy wedges in this sector, because consumption distortions become significant.

- The greater is the output $Y$ of the manufacturing sector, relative to domestic consumption C. A large output implies that specific-factor owners have much to gain from expanding the sector. A small consumption, in tum, implies that consumers have relatively little to Jose.

- The more concentrated is capital ownership across the population (i.e. the smaller is $\alpha^{K}$ ). Capital owners are also consumers and, as such, they suffer from market distortions. The bigger their group, the more they internalize the efficiency loss resulting from their lobbying.

- The less encompassing is the labor movement (i.e. the smaller is $\alpha^{\mathrm{U}}$ ). The reasons are the same as for capital owners. 
- The greater is the valuation B attached by the government to contributions by interest groups.

Table 1

Comparative Statics for the Equilibrium Distortions

\begin{tabular}{|c|c|c|c|c|c|}
\hline & $\epsilon^{\epsilon}$ & $Y / C$ & $\alpha^{\mathbf{k}}$ & $\alpha^{\mathrm{U}}$ & $\beta$ \\
\hline$\left(p^{0}-p^{*}\right) / p^{0}$ & - & $+(0)$ & - & - & + \\
\hline$\left(w^{0}-1\right) / w^{0}$ & - & $+(0)$ & - & - & + \\
\hline
\end{tabular}

The extent of product and labor market distortions also depends on whether tariff revenues are distributed to all the population or only to the individuals who are organized in interest groups. A simple way to see this is to replace the second equation in (20) into the first-order condition for profit maximization in (4), which yields:

$$
F_{L}\left(K_{y} L\right)=\frac{1}{\left[1-\frac{\beta-1}{\beta}\left(1-\alpha^{K}-\alpha^{U}\right) \phi^{A}\right] p^{*}+\frac{\beta-1}{\beta}\left(1-\alpha^{K}-\alpha^{U}\right) \phi^{A} p}
$$

When agricultural workers do not benefit from government transfers $\left(\phi^{A}=0\right)$, the above equation boils down to $F_{L}(K, L)=1 / p *$. In spite of a strictly positive tariff, the sectoral allocation of labor is optimal. Only consumption decisions are distorted by government policies. When tariff revenues are distributed to all the population, in turn, $\mathrm{F}_{\mathrm{L}}(\mathrm{K}, \mathrm{L})$ falls short of $1 / \mathrm{p}^{*}$ and employment in manufacturing is above its 
optimal level. However, as long as $\mathrm{Y} / \mathrm{C}<1$, the first equation in (20) implies that tariff barriers are lower when $\phi^{A}>0$. Redistribution of tariff revenues to agricultural workers thus reduces consumption distortions, while aggravating production distortions.

The results in Table 1 are very similar to those obtained by Helpman and Grossman (1994) for the structure of protection. As in their paper, the equilibrium level of market distortions combines the parameters that should be considered in a Ramsey rule for optimal taxation ( $\epsilon_{\mathrm{p}}$ and $\mathrm{Y} / \mathrm{C}$ ) with those that specifically correspond to the common agency setting $\left(\alpha^{K}, \alpha^{U}\right.$ and $\beta$ ).

However, by considering capital and labor as the relevant interest groups, our results also bridge the gap with the vast literature on the virtues of corporatism. ${ }^{8}$ If trade unions are narrowly defined, their members benefit form tarifi barriers and wage differentials, while imposing only a light burden on each individual consumer. As the number of beneficiaries from the distortions increases, the burden gets heavier, thus making organized workers internalize (as consumers) part of the resulting efficiency loss. In the limit, if all individuals are represented by either a trade union or a capital-owners association, which is the proper form of corporatism, then neither product nor labor markets are distorted. In this case, the common agency model yields efficient outcomes. Hence, inefficiency is due to incomplete representation.

\section{Social Pact}

A social pact can be viewed as a cartel between unionized workers and capital owners. The shift from non-cooperative to cooperative decision making by the two interest groups modifies the way political contributions are chosen, which in turn could affect the equilibrium level of product and labor market distortions. But this shift can have consequences on employment determination too. So far, it has been

8 See Bruno and Sachs (1985) and Calmfors and Driffill (1988), among others. 
assumed that firms are on their labor demand schedule. Each of them unilaterally determines its level of employment, given the level of prices and wages. Both capital owners and unionized workers could be better off though, if they jointly decided on employment. This would take them away from the labor demand schedule, to some more efficient contract schedule (McDonald and Solow, 1981).

Consider first the joint determination of political contributions under the assumption that firms are on their labor demand schedule. This assumption corresponds to the case of a cartel which is strong enough to set and monitor political contributions by capital owners, but not to interfere with their "right to manage" the firms. The cartel thus chooses the lobbying activities to maximize the joint welfare function $\mathbf{V}^{\mathbf{S}}$, defined as:

$$
v^{s}(p, w)=\alpha^{K} v^{K}(p, w)+\alpha^{U} v^{U}(p, w)-\lambda(p, w)
$$

where $\lambda$ is now the joint contribution of the cartel to the government. The government is still described as before; namely, it maximizes equation (8), except that $\lambda^{\mathbf{K}}+\lambda^{U}$ is now replaced by $\lambda$. Employment is also determined like in the previous model, and there are no side payments between capital owners and union members. Thus each individual in the cartel pays a contribution equal to $\lambda /\left(\alpha^{K}+\alpha^{U}\right)$.

The cartel's first-order conditions imply:

$$
\begin{aligned}
& \alpha^{\mathrm{K}} \mathbf{V}_{p}^{\mathrm{K}}+\alpha^{\mathrm{U}} \mathbf{v}_{\mathrm{p}}^{\mathrm{U}}=\lambda_{p} \\
& \alpha^{\mathrm{K}} \mathbf{v}_{w}^{\mathrm{K}}+\boldsymbol{\alpha}^{\mathrm{U}} \mathbf{v}_{w}^{\mathrm{U}}=\lambda_{w}
\end{aligned}
$$

while the government's first-order conditions are exactly as before. Combining equations (23) with the government's first-order conditions, it is easy to verify that the equilibrium policy is identical to that described in the previous sections. The distortion in the set up of the previous sections arises from the 
fact that one sector (agriculture) is excluded from the lobbying. The social pact does nothing to remedy that distortion.

There is a sense, however, in which the social pact could be welfare improving. The cost of influencing the government could be smaller if capital and labor cooperate with each other. Without the social pact, capital and labor unilaterally lobby the government to tilt policy in their desired direction. To some extent, therefore, they also lobby against each other (particularly in the case of the minimum wage), and the government free rides on that. Cooperation enables them to pay the government the minimum amount needed to get the policy they want.

To formally address this issue, we need to characterize the cartei contribution schedule in equilibrium. Like in section 4, we only consider truthful contribution schedules. Thus:

$$
\lambda^{s}\left(p, w ; z^{s}\right)=\operatorname{Max}\left[0, \alpha^{k} V^{X}(p, w)+\alpha^{U} V^{U}(p, w)-z^{s}\right]
$$

where $z^{S}$ is the reservation utility of the cartel. With only one lobby, equilibrium requires the government to be indifferent between taking the equilibrium contribution and taking no contribution at all and implementing the optimal policy of no intervention. Using the same notation as before, this indifference condition can be stated as:

$$
Q\left(p^{0}, w^{0}\right)+(\beta-1) \lambda^{s}\left(p^{0}, w^{0} ; z^{s}\right)-Q\left(p^{0} ; 1\right)=0
$$

where the last term on the left-hand side of (25) is aggregate (and government) welfare at free trade and no labor market intervention. Combining equations (24) and (25), we obtain the equilibrium reservation utility of the cartel:

$$
(\beta-1) z^{s}=Q\left(p^{0}, w^{0}\right)+(\beta-1)\left[\alpha^{K} V^{K}\left(p^{0}, w^{0}\right)+\alpha^{U} V^{U}\left(p^{0}, w^{0}\right)\right]-Q\left(p^{0}, 1\right)
$$


Recall that the social pact leads to the same equilibrium policy discussed in the previous sections. Hence, the question of whether the social pact reduces the equilibrium contributions received by the government amounts to a comparison of $z^{S}$ versus $z^{K}+z^{U}$. By equations (26) and (18), equilibrium contributions are smaller with the social pact than in a decentralized setting if the following condition is satisfied:

$$
\begin{gathered}
\sum_{x=K, U}\left[\Omega\left(p^{x}, w^{x}\right)+(\beta-1) \alpha^{x} V^{x}\left(p^{x}, w^{x}\right)\right]> \\
Q\left(p^{*}, 1\right)+\Omega\left(p^{0}, w^{0}\right)+(\beta-1) \alpha^{K} V^{K}\left(p^{0}, w^{0}\right)+(\beta-1) \alpha^{U} V^{U}\left(p^{0}, w^{0}\right)
\end{gathered}
$$

Applying the same arguments of section 4, condition (27) has a nice interpretation. The left-hrıd side of (27) is the maximum welfare attainable by the two coalitions consisting of the government plus one active lobby. The right-hand side is instead the maximum welfare attainable by the i $\cdots .$, roalitions consisting of the government plus both lobbies (i.e. the Nash equilibrium) and of the government alone (i.e., the free trade and no labor intervention outcome). If the left-hand side is larger than the right-hand side, then in the Nash equilibrium the government can extract more surplus, because it can credibly threaten to play one lobby against the other. It is precisely in this case that the social pact pays, in the sense that it reduces the amount of resources wasted in distributional activities.

Condition (27) is more likely to be fulfilled if the interests of capital and labor diverge from each other. For in this case $\left(p^{K}, w^{K}\right)$ and $\left(p^{U}, w^{U}\right)$ are very different, and the equilibrium policy $\left(p^{0}, w^{0}\right)$ is more likely to be a compromise that does not please either lobby very much. This conflict of interest is present in this model with regard to the wage policy, but not with regard to commercial policy. Hence, in the absence of specific assumptions on the functional form of preferences and technology, we 
cannot tell whether (27) is satisfied. Despite this ambiguity, note, however, that a necessary condition for a social pact to emerge is that it is a Pareto improvement for the lobbies involved. ${ }^{9}$

Next we turn to the second relevant issue in a social pact. Cooperation between capital owners and unionized workers may lead to their joint determination of the employment level. In this case, there is no need for the cartel to try to influence minimum wages. Indeed, side payments between capital and labor are now feasible by assumption, and they have to be either added to or subtracted from wages. If an agreement can be reached on the level of net workers' compensation, then the rationale to spend resources in making the government set some specific minimum wage level vanishes.

The cartel's objective function can thus be re-written as:

$$
V^{s}(p, L)=\alpha^{K} V^{X}(p, L)+\alpha^{U} V^{U}(p, L)
$$

where $L$ does not depend on $p$ and $w$ in the way described by the labor demand schedule in (4) anymore. The expected income of the cartel is:

$$
\alpha^{\mathrm{K}} I^{\mathrm{X}}+\alpha^{\mathrm{U}} \mathrm{I}^{\mathrm{U}} \equiv p \mathrm{pF}(\mathrm{K}, \mathrm{L})+\left(\alpha^{\mathrm{U}}-\mathrm{L}\right)+\left(\alpha^{\mathrm{K}} \phi^{\mathrm{K}}+\alpha^{\mathrm{U}} \phi^{\mathrm{U}}\right) \mathrm{T}(p, L)-\lambda(p)
$$

where the first term on the right-hand side is the value of output in the manufacturing sector, while the second term is the labor income earned by the fraction of union members who only find employment in agriculture. Maximizing $V^{S}$ with respect to $p$ and $L$ subject to $(7 S)$ leads to the following first-order conditions:

$$
\begin{aligned}
& v_{p}^{s}=\lambda_{p} \\
& v_{L}^{s}=0
\end{aligned}
$$

9 Since product and labor market distortions are not modified by the pact, the improvement can only result from a reduction in their political contributions. This reduction is thus a necessary condition of the social pact. 
The definition of the net cartel income in (7S) and that of tariff revenue in (5) imply, by the envelope theorem:

$$
\begin{gathered}
V_{p}^{s} \equiv F(K, L)+\left(\alpha^{K} \phi^{K}+\alpha^{U} \phi^{U}\right) T_{p}-\left(\alpha^{K}+\alpha^{\mathrm{V}}\right) C \\
V_{L}^{S}=p F_{L}-1+\left(\alpha^{K} \phi^{K}+\alpha^{U} \phi^{U}\right) T_{L}
\end{gathered}
$$

with $T_{L}$ and $T_{p}$ resulting from equation (5'). It follows that the employment level associated with a given domestic price $p$ is such that:

$$
F_{L}=\frac{1}{\left[1-\left(1-\alpha^{K}-\alpha^{U}\right) \phi^{\wedge}\right] p^{*}+\left(1-\alpha^{K}-\alpha^{U}\right) \phi^{A} p}
$$

When agricultural workers do not benefit from government transfers $\left(\phi^{A}=0\right)$, then $F_{L}=1 / p^{*}$, so that the sectoral allocation of labor is still optimal. Therefore, the social pact does not modify employment in manufacturing. But this is not true anymore if tariff revenues are distributed to all the population ( $\phi^{A}$ $>0$ ). In this case, the comparisen between equations (31) and (21) shows that for any given domestic price p, employment in manufacturing will be higher under a social pact than in the Nash equilibrium.

To analyze the consequences of the social pact on tariffs, recall that the government optimization problem remains the same as in equation (8), except that political contributions $\lambda$ depend now on p only. Replacing the government's first-order condition into the third equation in (28), and taking (5) into account, it can be shown that the rule setting the tariff rate is the same as in the absence of a social pact (first equation in (20)). But the tariff rate itself can be different, because the rule involves the ratio $\mathrm{Y} / \mathrm{C}$, which in turn depends on employment in manufacturing. Specifically, if agricultural workers benefit from government transfers ( $\phi^{A}>0$ ), then employment in manufacturing is higher under a social pact. For any given domestic price $\mathrm{p}$, the ratio $\mathrm{Y} / \mathrm{C}$ is higher too, and so is the equilibrium protection rate. 
To summarize, a social pact will modify the extent of product and labor market distortions if two conditions are met. First, the pact has to include employment as one of the variables capital owners and unionized workers negotiate on. In terms of the wage bargaining literature, firms have to give up their "right to manage". And second, the individuals who are not organized in interest groups have to benefit from government transfers. If these two conditions are fulfilled, the social pact will lead to larger distortions both in consumption (higher tariff rate) and in resource allocation (higher employment in manufacturing). But except for this particular case, the social pact should only affect the extent of political contributions, in the way that was described above.

\section{Reform Conditionality}

The model discussed in the previous sections can be used to analyze the role of a foreign agency, such as a donor country, or a multi-lateral organization like the World Bank, in shaping domestic economic policies. By making aid or subsidized loans conditional on economic reforms, this agency can be seen as an additional principal of the model competing with capital owners and unionized workers in influencing economic policies. Assume that the foreign agency is interested in improving the aggregate welfare of the recipient country. The question is: how should conditionality be designed in order to achieve this goal?

The welfare effects of aid conditionality depend on the timing of events, i.e., on whether the foreign agency pledges its contribution at the same time as domestic interest groups, or it rather commits to a contribution schedule, leaving room to the interest groups to lobby after the irreversible conditionality rule is announced. We consider first the case where the foreign agency and the domestic interest groups simultaneously choose their contribution schedules. The structure of the model is thus the same as before, except for the fact there is now an additional principal. 
Let $B(p, w)$ be the net transfer by the foreign agency. Conditionality is reflected in the fact that the transfer depends on the chosen economic policies, $p$ and $w$. Although this is not essential to the argument, assume the agency manages to get this transfer directly to the individuals, hence by-passing the government. In this case, the government's objective function becomes:

$$
V^{\mathcal{G}}(p, w)=(\beta-1)\left[\lambda^{\mathrm{X}}(p, w)+\lambda^{\mathrm{U}}(p, w)\right]+\Omega(p, w)+B(p, w)
$$

The objective function $\mathrm{V}^{\mathrm{F}}$ of the foreign agency, in turn, is given by:

$$
{ }^{v P}(p, w) \equiv Q(p, w)+(1-\theta) B(p, w)
$$

where $\theta>1$ represents the opportunity cost of the agency's funds. If $\theta=1$, financing the transfer would not be a problem, and the agency would care only about aggregate welfare in the recipient country.

Since the foreign agency and domestic interest groups simultaneously set their contribution schedules, the interest groups take the net transfer B as given. Therefore, their first-order conditions remain the same as before (see equations (11)). With regard to the foreign agency, it maximizes its objective function when:

$$
\begin{aligned}
& B_{F}=\frac{1}{\theta-1} \cdot Q_{p} \\
& B_{\nabla}=\frac{1}{\theta-1} \cdot O_{\nabla}
\end{aligned}
$$

Not surprisingly, the slopes of its contribution schedule with respect to the economic policy arguments $p$ and $w$ have the same signs as the slopes of the aggregate welfare function $\Omega$ with respect to these two argumenis.

Finally, the government's first-order conditions are: 


$$
\begin{aligned}
& v_{p}^{G}=(\beta-1)\left(\lambda_{p}^{X}+\lambda_{p}^{U}\right)+Q_{p}+B_{p}=0 \\
& v_{w}^{O}=(\beta-1)\left(\lambda_{w}^{X}+\lambda_{w}^{Y}\right)+Q_{w}+B_{w}=0
\end{aligned}
$$

After replacing the first-order conditions for the foreign agency and the domestic interest groups, equation (34) can be re-written as follows:

$$
\begin{aligned}
& V_{p}^{O}=\hat{\beta} \alpha^{K} V_{p}^{K}+\hat{\beta} \alpha^{U} V_{p}^{U}+\left(1-\alpha^{K}-\alpha^{U}\right) V_{p}^{A}=0 \\
& V_{w}^{O}=\hat{\beta} \alpha^{K} V_{w}^{K}+\hat{\beta} \alpha^{U} V_{w}^{U}+\left(1-\alpha^{K}-\alpha^{U}\right) V_{w}^{A}=0
\end{aligned}
$$

with:

$$
\hat{\beta}=\frac{1+\beta(\theta-1)}{\theta}<\beta
$$

Therefore, reform conditionality by the foreign agency has the effect of reducing the weight of the individuals who are represented by interest groups in the social welfare function maximized by the government. As the opportunity cost $\theta$ of the funds pledged by the agency decreases, this weight gets closer to the one that would be used by a Pigouvian policy maker. In the limit, if $\theta$ was equal to one, then conditionality would lead to first-best policies.

What does the analysis suggest about the optimal design of conditionality? To answer, note first of all that the similarity between equations (35) and (13) also allows to derive the signs of $\boldsymbol{\Omega}_{\mathbf{p}}$ and $\boldsymbol{\Omega}_{\mathbf{w}}$ in equilibrium and, therefore, the nature of the reforms the foreign agency should help implementing through conditionality. The analysis is identical to that in section 4. Equation (13) in that section showed that equilibrium protection was too high $\left(\Omega_{\mathrm{p}}<0\right)$ irrespective of whether agricultural workers receive transfers from the government or not. Equation (33), in turn, implies $\mathbf{B}_{\mathbf{p}}<0$, which means that net transfers by the foreign agency should be conditional on trade liberalization. 
This conclusion does not apply to labor market liberalization. In the case where tariff revenues are distributed evenly to all the population, by (13') $\Omega_{w}<0$. Taken literally, this result would mean that the foreign agency should push for higher (not lower) wages in the protected sector of the economy. In the more realistic case where government transfers go only to the individuals who are organized in interest groups, $\Omega_{w}=0$, which implies that transfers by the foreign agency should not be conditional on labor market policies. This result follows from the complementary that was noted above, between product and labor market distortions. If the foreign agency succeeds in inducing the government to reduce tariffs, labor market policies will automatically be moved in the right direction by domestic political forces.

Consider now the case where the foreign agency commits to a contribution schedule, and afterwards interest groups lobby for government intervention. In this case, each of the groups internalizes the effects of the transfer by the foreign agency on the well being of its members. To take an example, if the transfer is conditional on trade liberalization, by lobbying for higher tariffs an interest group may now be raising the income its members get as factor owners, but at the same time it would reduce the income they receive from the foreign agency.

The first-order conditions of interest groups now are:

$$
\alpha^{x} V_{p}^{x}+\alpha^{x} B_{p}=\lambda_{p}^{x}, \alpha^{x} V_{w}^{x}+\alpha^{x} B_{w}=\lambda_{w}^{x}, x=K, U
$$

Since the first-order conditions for the foreign agency and for the government are the same as before (equations (33) and (34) respectively), the equilibrium is characterized by the same expressions as (35) above, but with the weight of interest group members replaced by $B^{*}$, with:

$$
\beta^{*}=\frac{1+\beta(\theta-1)+(\beta-1)\left(\alpha^{\mathrm{X}}+\alpha^{5}\right)}{\theta+(\beta-1)\left(\alpha^{\mathrm{X}}+\alpha^{\mathrm{V}}\right)}<\hat{\beta}
$$


Thus, economic policies get closer to the first best when the foreign agency commits to its optimal conditionality rule than when it tries to influence government choices simultaneously with domestic interest groups. This is because a conditionality clause announced well in advance increases the cost of large departures from first-best policies. As a result, the equilibrium lobbying is smaller, and so are the resulting equilibrium distortions.

Finally, a conditionality clause changes slightly the equilibrium reservation utilities, $z^{\mathbf{K}}$ and $z^{U}$. Since the logic discussed in section 4, however, still applies, we do not derive once more the equilibrium contribution functions of the lobbies.

\section{Electoral Competition}

The previous model can also be extended to include electoral competition between different parties. In developing countries, the political system is uften polarized between ideological parties who represent the interests of organized labor and capital owners. We will call them for simplicity (but with inaccuracy) left- and right-wing parties. The results of the previous section, on reform conditionality, suggest a natural question: can a conditional aid program by a foreign agency have electoral consequences? And if so, in what direction and with what welfare effects? In this sub-section we sketch a simple extension of the model that can address these questions.

Consider first a world without any conditional aid program. Suppose that there are two possible government types, left and right. The left-wing government maximizes a social welfare function like (8) above, except that welfare of union members receives a higher weight. Similarly, the right-wing government assigns a higher weight to the welfare of capital owners. Specifically, for the left-wing government the term $\Omega$ in equations (8) and (9) is replaced by:

$$
Q^{L}(p, w) \equiv \alpha^{K} V^{K}(p, w)+\alpha^{U} V^{U}(p, w)+\left(1-\alpha^{K}-\alpha^{U}\right) V^{A}(p, w)
$$


where $\hat{Q}^{U}>a^{U}$, while the right-wing government has an analogous welfare function, but with the highest weight corresponding to capital owners.

Suppose further that the tariff revenue only goes to unionized workers and capital, and not to the agricultural sector. The results in the previous sections imply that, from the point of view of maximizing the ideological social welfare function defined in equation $\left(9^{\prime}\right)$, the equilibrium policy with lobbying always involves too much protection. They also imply that the welfare of agricultural workers is unaffected by the wage policy.

Finally, suppose that the two government types run for office in an electoral contest, before lobbying takes place and before policy is chosen. All capital owners vote for the right-wing government, while all unionized workers vote for the left-wing government. Assuming that neither union members nor capital owners reach a majority on their own, the election outcome is determined by workers in the agricultural sector. Voters' rationality implies that the agricultural voter compares the equilibrium outcome when either government type is in office, and votes for the candidate that yields the higher equilibrium welfare. The welfare of voters in the agricultural sector depends on the policy $\mathrm{p}$ chosen by the elected government, as well as on other political dimensions that we do not attempt to model. These other dimensions are captured by the realization of a random variable, $\mathrm{g}$, distributed in the population of agricultural workers according to the cumulative distribution function $\mathbf{G ( . ) .}$

Specifically, agricultural worker $i$ votes for the left-wing candidate if:

$$
V^{A}\left(p^{R}\right)+g^{1} \leq V^{A}\left(p^{L}\right)
$$

where $\mathbf{p}^{\mathbf{R}}$ and $\mathrm{p}^{\mathrm{L}}$ denote the protective policy chosen by the right- and left-wing governments respectively, and $\mathrm{V}^{\mathrm{A}}(\mathrm{p})$ is the welfare of agricultural workers under that policy. The variable $\mathrm{g}^{\mathrm{i}}$ captures the effect of the other (non-modeled) political dimensions, as perceived by voter i. Thus, if the two 
parties choose the same equilibrium policy once elected, the right-wing party captures the vote of the $i$-th agricultural worker if $\mathrm{g}^{\mathrm{i}}>0$ while the left-wing party captures it if $\mathrm{g}^{\mathrm{i}}<0$.

Under this notation, the left-wing party wins the election if:

$$
G\left[V^{\wedge}\left(p^{L}\right)-V^{\wedge}\left(p^{R}\right)\right] \geq \frac{1 / 2-\alpha^{U}}{1-\alpha^{R}-\alpha^{U}}
$$

where the left-hand side is the fraction of agricultural workers in favor of the left-wing government, given the equilibrium policy of both types of government.

Next, consider what happens if, beiore the election takes place, the country is faced with a conditional aid program by a foreign agency. For simplicity, let the program be conditional on the tariff policy only. The net transfer is thus a lump sum $B(p)$ to each citizen, conditional on the policy $p$ implemented after the election. This has the effect of altering the agricultural voters preferences for the election outcomes. The left-wing party now wins the election if:

$$
G\left[V^{A}\left(p^{L}\right)-V^{A}\left(p^{R}\right)+B\left(p^{L}\right)-B\left(p^{\mathbb{R}}\right)\right] \geq \frac{1 / 2-\alpha^{U}}{1-\alpha^{X}-\alpha^{U}}
$$

As in equation (39), the first term measures the fraction of agricultural workers in favor of the left-wing government. This fraction is now affected by the conditional aid program, in two ways. Directly, as the transfer B is larger with the government who implements the lower tariff. This effects obviously favors the more free trade party. And indirectly, since the conditional aid program presumably induces both government types to choose a different policy $p$ than they would have otherwise chosen. This second indirect effect can go either way, and favors the party who is more responsive to the conditional aid program. 
Summarizing, even if the policy is closen after the elections, the presence of a conditional aid program has a political effect, since its anticipation by the voters can influence the election outcome. Typically, the aid is (and ought to be) conditional on a low degree of protection. In this case, and abstracting from the indirect effect mentioned above, the aid program creates a bias in favor of parties advocating free trade (or, symmetrically, a bias against parties advocating high degrees of protection). From the point of view of the foreign agency, this political effect is not undesirable, since it makes it more likely that trade liberalization is implemented. Naturally, this conclusion follows from a set up in which protection is the result of influence activities, and is not chosen by a benevolent social planner.

\section{Concluding Remarks}

This paper deals with the interaction of product and labor market distortions, and how to cope with them, when governments are responsive to pressures applied by interest groups. Its two main contributions are in two areas.

At the analytical level, the paper extends the common agency model beyond the trade policy issues considered so far, to the analysis of the simultaneous determination of product and labor market interventions. The common agency model is a promising analytical tonl to analyze political influences on policy formation. This is because of its ability to derive endogenous policies from first principles, without sacrificing tractability (Rodrik, 1994). By taking labor markets and trade unions explicitly into account, our paper brings the capital-labor relationship into the common agency set up. Although more traditional than trade policy issues, this relationship has received less attention in the political economy literature. By the same token, our paper provides a micro-foundation for the discussion on the virtues of corporatism and the consequences of social pacts. More generally, it shows that the nature and direction of the labor market distortions induced by lobbying activities is not obvious, because of secondbest arguments. 
At the policy level, the main contribution of the paper is the analysis of the optimal conditionality clauses on product and labor market reforms to be imbedded in aid programs by multi-lateral organizations and donor countries. Policy lending has been at the core of the development business for more than one decade. Poor performance is seen indeed as the outcome of "bad" economic policies, including binding distortions in product and labor markets. Bad policies, in turn, are explained as the result of "politics". Yet, there is no analytical model to deal with optimal conditionality when economic policies are shaped by politics. The main result we obtain here is that labor market distortions ought not to be targeted because they are likely to adjust in the desired direction once trade distortions are removed or diminished. This non-intuitive result highlights the risks of inferring conditionality rules from partial equilibrium analysis when there are distortions to two markets, and they are both endogenous. 


\section{References}

Bernheim, B. and M. Whinston (1986): "Common Agency", Econometrica, 54(4), p. 923-942, July.

Bruno, M. and J. Sachs (1985): The Economics of Worldwide Stagflation, Harvard University Press, Cambridge, Mass.

Calmfors, L. and J. Driffill (1988): "Bargaining Structure, Corporatism and Macroeconomic Performance", Economic Policy, 6, p. 14-61, April.

Grossman, G. and E. Helpman (1994): "Protection for Sale", American Economic Review, 84(4), p.833850, September.

McDonald, I. and R. Solow (1981): "Wage Bargaining and Employment", American Economic Review, 71, p. 896-908.

Oswald, A. (1985): "The Economic Theory of Trade Unions: an Introductory Survey", Scandinavian Journal of Economics, 87(2), p. 160-193.

Rodrik, D. (1994): "What Does the Political Economy Literature on Trade Policy (not) Tell Us that We Ought to Know", in Handbook of International Economics, Vol. III, North Holland, forthcoming. 


\section{Pollcy Reaearch Working Paper Sorlee}

\begin{tabular}{|c|c|c|c|c|}
\hline & Thle & Author & Date & $\begin{array}{l}\text { Contact } \\
\text { for paper }\end{array}$ \\
\hline WPS1397 & $\begin{array}{l}\text { Aro Private Capltal Flows to } \\
\text { Developing Countrleo Sustainable? }\end{array}$ & $\begin{array}{l}\text { Un Dadush } \\
\text { Ashok Dhareshwar } \\
\text { Ron Johannos }\end{array}$ & Docomber 1994 & $\begin{array}{l}\text { J. Queon } \\
33740\end{array}$ \\
\hline WPS1398 & The Cost of Air Pollution Abatement & $\begin{array}{l}\text { Raymond S. Hartman } \\
\text { David Whocler } \\
\text { Manjula Singh }\end{array}$ & December 1994 & $\begin{array}{l}\text { E. Schaper } \\
33457\end{array}$ \\
\hline WPS1399 & $\begin{array}{l}\text { How Important to India's Poor is the } \\
\text { Urban-Rural Composition of Growth? }\end{array}$ & $\begin{array}{l}\text { Martin Ravallion } \\
\text { Gaurav Datt }\end{array}$ & December 1994 & $\begin{array}{l}\text { P. Cook } \\
33902\end{array}$ \\
\hline WPS1400 & $\begin{array}{l}\text { Technical and Markeling Support } \\
\text { Systems for Successtul Small and } \\
\text { Medlum-Size Enterprises in Four } \\
\text { Countries }\end{array}$ & $\begin{array}{l}\text { Brian Levy wilh } \\
\text { Albert Berry, Motoshige Itoh, } \\
\text { Linsu Kim, Jeffrey Nugent, } \\
\text { and Shujiro Urate }\end{array}$ & $\begin{array}{l}\text { December } 1994 \\
\text { h. }\end{array}$ & $\begin{array}{l}\text { D. Evans } \\
38526\end{array}$ \\
\hline WPS1401 & $\begin{array}{l}\text { Colombia's Small and Medium-Size } \\
\text { Exporters and Their Support Systems }\end{array}$ & $\begin{array}{l}\text { Albert Berry } \\
\text { Jose Escandon }\end{array}$ & December 1994 & $\begin{array}{l}\text { D. Evans } \\
38526\end{array}$ \\
\hline WPS1402 & $\begin{array}{l}\text { Indonesia's Small and Medium-Size } \\
\text { Exporters and Their Support Systen.s }\end{array}$ & $\begin{array}{l}\text { Albert Berry } \\
\text { Brian Levy }\end{array}$ & December 1994 & $\begin{array}{l}\text { D. Evans } \\
38526\end{array}$ \\
\hline WPS1403 & $\begin{array}{l}\text { Small and Medium-Size Enterprise } \\
\text { Support Policies in Japan }\end{array}$ & $\begin{array}{l}\text { Motoshige Itoh } \\
\text { Shujiro Urata }\end{array}$ & December 1994 & $\begin{array}{l}\text { D. Evans } \\
38526\end{array}$ \\
\hline WPS1404 & $\begin{array}{l}\text { The Republic of Korea's Small and } \\
\text { Medlum-Size Enterprises and Their } \\
\text { Support Systems }\end{array}$ & $\begin{array}{l}\text { Linsu KIm } \\
\text { Jettrey B. Nugent }\end{array}$ & December 1994 & $\begin{array}{l}\text { D. Evans } \\
38526\end{array}$ \\
\hline WPS1405 & Growth and Poverty in Aural India & $\begin{array}{l}\text { Martin Ravallion } \\
\text { Gaurav Datt }\end{array}$ & January 1995 & $\begin{array}{l}\text { WOR } \\
31393\end{array}$ \\
\hline WPS1406 & $\begin{array}{l}\text { Structural Breaks and Long-Run } \\
\text { Trends in Cornmodity Prices }\end{array}$ & $\begin{array}{l}\text { Javier Loón } \\
\text { Raimundo Soto }\end{array}$ & January 1995 & $\begin{array}{l}\text { P. Luz } \\
31320\end{array}$ \\
\hline WPS1407 & $\begin{array}{l}\text { Pakistan's Agriculture Sector: } \\
\text { Is } 3 \text { to } 4 \text { Percent Annual Growth } \\
\text { Sustainable? }\end{array}$ & Rashid Faruqee & January 1995 & $\begin{array}{l}\text { F. Willie } \\
82262\end{array}$ \\
\hline WPS1408 & $\begin{array}{l}\text { Macroeconomic Management and } \\
\text { Intergovemmental Relations in } \\
\text { China }\end{array}$ & Jun Ma & January 1995 & $\begin{array}{l}\text { C. Jones } \\
37754\end{array}$ \\
\hline WPS1409 & $\begin{array}{l}\text { Restructuring Uganda's Debt: } \\
\text { The Commercial Debt Buy-Back } \\
\text { Operation }\end{array}$ & Kapil Kapoor & January 1995 & $\begin{array}{l}\text { E. Spano } \\
35538\end{array}$ \\
\hline WPS1410 & $\begin{array}{l}\text { Macroeconomic Effects of Terms- } \\
\text { of-Trade Shocks: The Case of Oil- } \\
\text { Exporting Countries }\end{array}$ & $\begin{array}{l}\text { Nikola Spatafora } \\
\text { Andrew Wamer }\end{array}$ & January 1995 & $\begin{array}{l}\text { J. Queen } \\
\mathbf{3 3 7 4 0}\end{array}$ \\
\hline
\end{tabular}


Pollcy Research Working Paper Serles

Title

WPS1411 Income Inequality, Welfare, and Poverty: An Illustration Using Ukrainian Data

WPS1412 Foraign Technology Imports and Economic Growth in Developing Countries

WPS1413 Endogenous Distortions in Product and Labor Markets

WPS1414 The Wortd Bank and Legal Technical Assistance: Initial Lessons
Author

Nanak Kakwani

Xlaoming Zhang

Heng-fu Zou

Martin Rama

Guido Tabellini

The World Bank

Legal Department
Contact

Date

for paper

January 1995

G. Evans 85783

January 1995

C. Jones 37754

January 1995

S. Fallon 38009

January 1995

K. Mathernová 82782 
